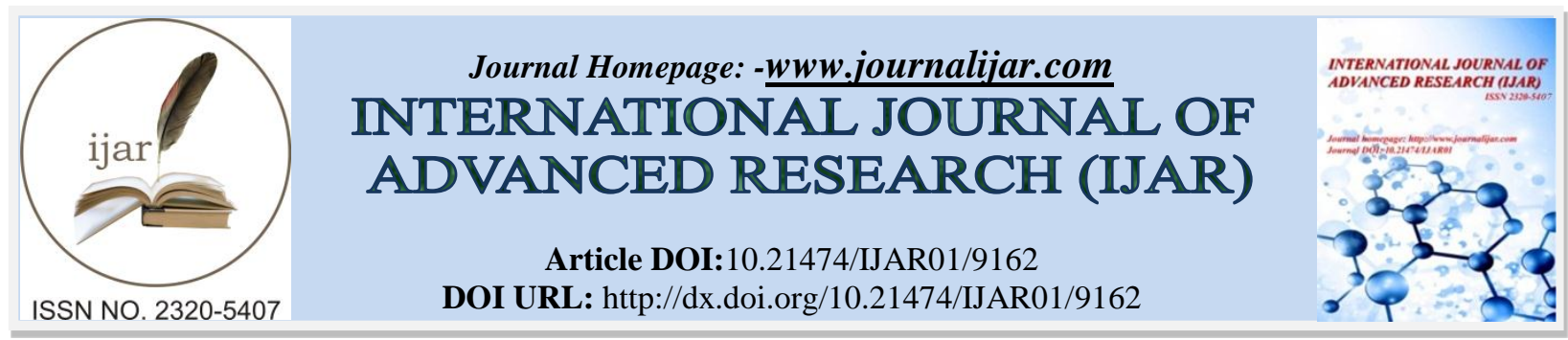

RESEARCH ARTICLE

\title{
IMPLEMENTATION OF BIOREMEDIATION CONCEPT IN THE TREATMENT OF TEXTILE EFFLUENT.
}

\author{
Sumithra Salla. \\ Assistant Professor, Dept of Biotechnology, Chaithanya Bharathi Institute of Technology (CBIT), Gandipet, \\ Hyderabad, India.
}

\section{Manuscript Info}

Manuscript History

Received: 24 March 2019

Final Accepted: 26 April 2019

Published: May 2019

Key words:-

Bioremediation, Synthetic Dyes, Textile effluent, Waste water.

\section{Abstract}

Around the world, dye wastewater has turned out to be one of the fundamental reasons for several environmental pollution problems because of the increased noteworthy demand for textile products and the relative increment in production and application of engineered dyes. As a consequence, in the furtherance of waste water treatment, it has become both a major concern and imperative to treat the industrial effluent that originates from textile and dye stuff plants accounting for a continuous discharge of remnant dyes to the environment. For the same, the efficient treatment of this textile effluent in an eco- friendly manner has gained a lot of attention in contemporary days, reasoning from which is where the concept of Bioremediation intervenes and which was the core aspect of our project. In the present study, our focus in it's totality has been on operating three different bacterial species namely Bacillus, Pseudomonas \& Staphylococcus Aureus in pursuit of treating the industrial effluent incorporating synthetic dyes.

Copy Right, IJAR, 2019,. All rights reserved.

\section{Introduction:-}

Population explosion, to the tune of 7.2 billion, along with excessive use of natural resources and a variety of anthropogenic activities, has resulted in a large-scale contamination of the environment, especially the soil and the groundwater. Contamination in the environment is an ever-increasing phenomenon, and often, regulatory systems and cleaning operations are not commensurate with waste generation. This is true with the large amounts of synthetic dyes that are released into the soil and water resources there by polluting the planet which evidently is responsible for a lot of distress. It has therefore become imperative to search for effective and low-cost methods that follows and stimulates the mechanisms of nature's cure, especially. For this reason, Bioremediation technologies resting upon the vast potential of biodiversity for the monitoring and abatement of environmental pollution have to be put in practice across the world.

The present project was embarked upon to investigate the potency of locally isolated bacteria namely Pseudomonas $\mathrm{Sp}$, Bacillus Subtilis and Staphylococcus Aureus to degrade textile effluents mainly consisting of synthetic dyes collected locally from different textile dyeing industries in \& around Hyderabad, thereby presenting an insight into the media engineering and parameters associated with the activity of decolorization of the dyes by the three selected bacterial species, along with their comparative analysis. Thus, our work aims to (I) screen and identify the most effective of the three above mentioned bacteria (II) study the potency of these isolates in dye degradation, (III) 
optimization of media and culture conditions associated with degradation and (IV) Fabrication of the appropriate product consisting of immobilized bacteria suitable for dye decolorization.

\section{Materials \& methodology:-}

Materials: -

1. Equipment: - Glassware (Borosil), Centrifuge (Eltek), pH meter (Essel), laminar air flow (Aircon- Mumbai), Incubator, Autoclave (Robot), Hotplate (Bio-techniques), Microscopes (Blisco), Precision balance (National), Photo colorimeter (EI), Micropipette.

2. Dyes: - Black, Blue, Green, Red, Crystal violet

3. Media: - Nutrient Agar Medium, Mannitol Salt Agar Medium, Pseudomonas Isolation Medium

\section{Methodology: -}

In pursuit of carrying out the bioremediation of the selected dyes with the stipulated organisms being Pseudomonas Sp, Bacillus Subtilis \& Staphylococcus Aureus, the below summarized methodologies have been consummated: -

Media preparation

Isolation of the stipulated micro-organisms

Tests for Identification \& Characterization of the micro-organisms namely:

Indole Test, Methyl Red and Voges-Proskauer Test, Vogus Proskauer Test, Citrate Utilization Test

\section{Biodegradation of textile effluents by using different dyes:}

1. Sampling and analysis of the effluent has been consummated

2. Followed by Isolation, screening and identification of dye decolorizing bacteria from effluent: These isolates were screened for their ability to decolorize the dyes in liquid culture. The screening process in liquid media was carried out by inoculating a loop full of cultures exhibiting clear zones into nutrient broth containing dyes under static conditions.

\section{Decolorization Assay:}

The decolorization process was carried out using shaking and static cultures by inoculating $1 \mathrm{ml}$ of precultured (O.D. 0.85-1) stipulated species into $100 \mathrm{ml}$ of sterilized nutrient broth in a $250 \mathrm{ml}$ Erlenmeyer flask and incubated on a rotary shaker $(130 \mathrm{rpm})$ at $35^{\circ} \mathrm{C}$ for $24 \mathrm{~h}$. Filter sterilized $(0.22 \lambda \mathrm{m})$ dye $(100 \mathrm{mg})$ was added to the culture and incubated in shaking conditions at $140 \mathrm{rpm}$ and in static conditions at room temperature for decolorization to occur. At regular intervals, $4 \mathrm{ml}$ sample was withdrawn aseptically and centrifuged at $8500 \mathrm{rpm}$ for $15 \mathrm{~min}$. The cell free supernatant was used to determine the percentage decolorization of the dye with the following formula. The decolorizing activity was expressed in terms of the percentage decolorization by the modified method described previously.

$\%$ Decolorization: Initial absorbance - final absorbance Initial absorbance $\times 100$

Immobilization of cells:

Agar Solution and Inoculi were prepared separately where $50 \mathrm{ml}$ of each of the inoculi was prepared and incubated for $24 \mathrm{hrs}$. A solution containing $3 \%$ bacteriological agar $(100 \mathrm{ml})$ in a $250 \mathrm{ml}$ Erlenmeyer flask was sterilized and cooled to $40-45^{\circ} \mathrm{c}$. The inoculi with OD600nm $=0.1$ which correspond to $109 \mathrm{cfu} / \mathrm{ml}$ was mixed with the prepared agar plates and solidification occurred after 10minutes. The solidified agar block was cut into equal size cubes, then added to sterile $0.1 \mathrm{ml}$ phosphate buffer $(\mathrm{pH} 7.0)$, and kept in the refrigerator (1hr) for curing. Phosphate buffer was decanted and the cubes were washed with sterile distilled water 3 to 4 times before used. Two litres of the effluent supplemented with Minimum Basal medium in g/l: $\mathrm{NaCl}(0.8), \mathrm{MgSO}_{4} \cdot 7 \mathrm{H}_{2} \mathrm{O}(0.001) ; \mathrm{KH}_{2} \mathrm{PO}_{4}(2) ; \mathrm{NaNO}_{3}(2)$; $\mathrm{CaCl}_{2} \cdot 2 \mathrm{H}_{2} 0(0.5), \mathrm{NaHPO}_{4} \cdot 12 \mathrm{H}_{2} \mathrm{O}(2)$, sterilized in an autoclave at $121^{\circ} \mathrm{c}$ for $15 \mathrm{mins}$. One thousand $\mathrm{ml}$ of the sterilized effluent was dispensed into 5litres bioreactor fitted with air sparge aseptically. $30 \mathrm{gms}$ each of the immobilized bacterial cells was added Physicochemical Parameters were determined at every five days intervals to monitor the progress of bioremediation for 15days.

\section{Results:-}

As per the conducted research, the behaviour and effect of the stipulated bacteria on the different dyes is as summarized below:

1. The Bacillus Subtilis on inoculation in textile effluent - the change in colour was observed from thick colour of the dye to colourless. 
2. The Pseudomonas on inoculation in textile effluent - the change in colour was observed from thick colour of the dye to colourless.

3. Staphylococcus aureus on inoculation in textile effluents - there was absolutely no change in colour observed.

Nonetheless, the Bacillus Subtilis apparently had a greater effect on the dye decolorization and promisingly with greater potency of bioremediation. Thence, below are the results for several tests consummated as part of the study especially for Bacillus Subtilis.

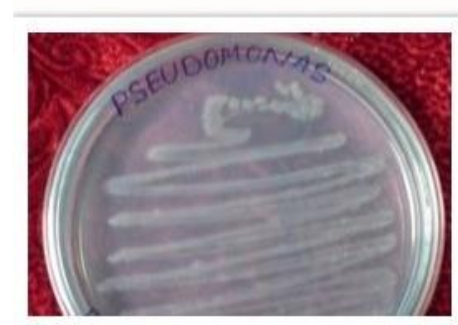

Pseudomonas Sp

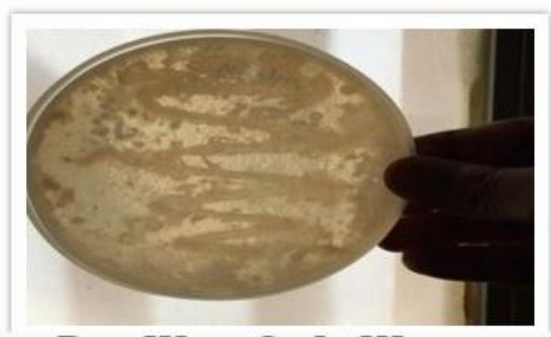

Bacillus Subtilis

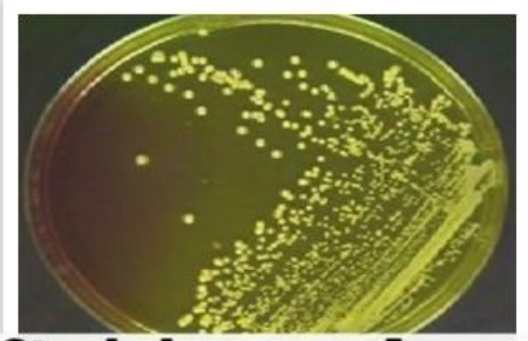

Staphylococcus Aureus

Figure 1:-Growth of all the stipulated bacterial species

\section{Effect of Different Sugars:}

The effect of different sugars was studied where the Production medium was prepared by substituting the maltose with different sugars as mentioned in Table 1, with maltose as control in different flasks and the $\mathrm{pH}$ amended to 7.0 $\&$ then autoclaved followed by inoculating the flasks with $5 \%$ of overnight grown cultures, the samples of which were estimated after $48 \mathrm{hrs}$ of incubation.

\begin{tabular}{|c|c|}
\hline $\mathbf{C O}_{\mathbf{2}}$ SOURCE & Absorbance at 620nm \\
\hline GLUCOSE & 22 \\
\hline LACTOSE & 15 \\
\hline STARCH & 46 \\
\hline MALTOSE & 16 \\
\hline MANNITOL & 36 \\
\hline
\end{tabular}

Table 1:-Estimation of effects of different sugars

\section{Effect of Different pH levels:}

The effect of various $\mathrm{pH}$ ranges was investigated where the Production medium was prepared with Lactose as substrate and distributed $25 \mathrm{ml}$ each into different flasks with $\mathrm{pH}$ adjusted to different ranges as mentioned in below table and labelled respectively and then autoclaved followed by inoculating the flasks with 5\% of Overnight grown cultures, which were then incubated at $37^{\circ} \mathrm{C}$ for $48 \mathrm{hrs}$.

\begin{tabular}{|c|c|}
\hline PH & Absorbance at 620nm \\
\hline PH 5 & 13 \\
\hline PH 6 & 25 \\
\hline PH 7 & 12 \\
\hline PH 8 & 06 \\
\hline PH 9 & 12 \\
\hline
\end{tabular}

Table 2:-Estimation of effects of different $\mathrm{pH}$ levels

\section{Effect of Different Temperature ranges:}

The effect of various temperature ranges was evaluated where the Production broth was prepared with lactose as substrate and dispensed $25 \mathrm{ml}$ each into four different flasks with the $\mathrm{pH}$ of each flask adjusted to 8.0 then autoclaved. Then overnight grown cultures were inoculated into each flask where the four flasks were incubated at $0^{\circ} \mathrm{C}, \mathrm{RT}, 37^{\circ} \mathrm{C}$ and $45^{\circ} \mathrm{C}$ respectively for $48 \mathrm{hrs}$ and then were collected and assayed with results as shown in the Table 3. 


\begin{tabular}{|c|c|}
\hline $37^{\circ} \mathrm{C}$ & 27 \\
\hline $28^{\circ} \mathrm{C}$ & 20 \\
\hline $40^{\circ} \mathrm{C}$ & 16 \\
\hline $4^{\circ} \mathrm{C}$ & 14 \\
\hline
\end{tabular}

Table 3:-Estimation of effects of different Temperature levels

\section{Result observed with immobilized cells in agar blocks:}

The agar blocks containing the pseudomonas and bacillus separately were immersed in phosphate buffer at ph 7.0 then they were introduced into the effluents. The results have showed that there is decolorization of the dye. The absorbance was measured at $620 \mathrm{~nm}$. The measurement was carried out with the effluent before treatment with the blocks and after treatment with the blocks (see Figure 2). The results were given in the Table 4. The results have showed that the immobilized cells were able to degrade the dye in a period of 24 hours.

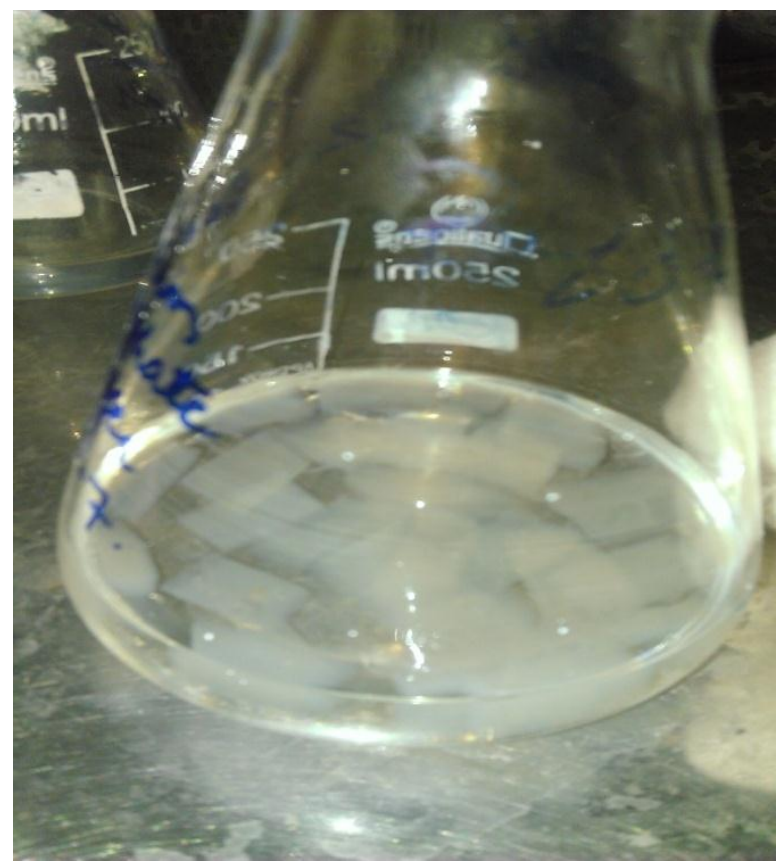

Figure 2:-Immobilized cells in agar blocks

\begin{tabular}{|c|c|}
\hline OD 620 of the effluent & OD 620 of the effluent after treatment with Blocks \\
\hline 0.32 & 0.21 \\
\hline 0.38 & 0.29 \\
\hline 0.43 & 0.33 \\
\hline 0.29 & 0.18 \\
\hline
\end{tabular}

Table 4:-OD of the effluent at $620 \mathrm{~nm}$

\section{Discussions:-}

Throughout India, there is grave concern and constant attention given to the treatment of industrial effluent from textile and dye manufacturing units. Several researchers have demonstrated the possibility of utilizing microorganisms for bio-treatment of textile wastewater. In India, most textiles units are scattered and/or operated from private homes. Therefore, it is necessary to collect and treat the waste in common effluent treatment plants. Interest in the bioremediation of pollutants using bacteria has intensified in recent years, as many researches demonstrated the efficacy of bacterial bioremediation over fungal and actinomycetes. B. subtilis with strong decolorizing ability was isolated from textile effluent to decolorize the textile ago dye crystal violet $100 \mathrm{mg}$ within $24 \mathrm{~h}$ in aerobic and static conditions. The percentage of decolorization of crystal violet by B. subtilis strain under static conditions was $90 \%$ within $24 \mathrm{~h}$ of incubation which was equal to a similar study but with $35 \mathrm{~h}$ of incubation. In another study conducted with Pseudomonas putida, P. fluorescence, Bacillus cereus and Stentrophomonas acidaminiphila to decolorize Acid Red 88 showed their efficiencies at 35\%, 31\%, 40\% and 50\%, respectively. 
Under aerobic conditions, Azo dyes are generally resistant to attack by bacteria. The optimal $\mathrm{pH}$ for complete decolorization of Crystal violet was at 8 which is slightly in accordance with Cosmarium spp. decolorizing malachite green at pH 9 and Klebsiella pneumonia which completely degraded Methyl Red in pH range of 6 to 8 . Optimal growth temperature was found to be $35^{\circ} \mathrm{C}$ which is consistent with the highest decolorization temperature in our study. Maximum potential of Pseudomonas sp. to decolorize Malachite green, fast green was noticed at $37^{\circ} \mathrm{C}$.

\section{Conclusion:-}

The investigation presumed that $\mathrm{pH}$, temperature and different carbon and nitrogen sources impact color expulsion proficiency by B. subtilis. This demonstrates the confined bacterium can possibly degrade the textile colours and resolve the issue of superfluous colours present in the effluents of textile enterprises. Further pilot scale thinks about are required with such strains for real modern applications, and point by point ponders are expected to investigate the component included. Despite the fact that decolorization is a moving procedure to both material industry and wastewater treatment, the consequence of these discoveries and writing recommends an incredible potential for such microbes to be utilized to expel shading from colour wastewaters. B. subtilis demonstrated decolorizing movement through a debasement instrument instead of adsorption. This perception has built up that microscopic organisms are versatile in nature and can corrupt contaminants. Be that as it may, capability of the strains should be exhibited for their application in treatment of genuine colour bearing wastewaters utilizing suitable bioreactors.

With the application of traditional wastewater treatment involving enormous cost and continuous input of chemicals, which becomes uneconomical and causes further environmental damage, there is every mandate for both economical and eco-friendly methods to be emerged \& employed.

Ergo, the present research conducted manifests that Bioremediation has the potential to restore sullied environmental conditions reasonably yet adequately, yet an absence of data about the variables controlling the development and digestion of microorganisms in dirtied situations frequently constrains its usage. In any case, fast advances in the comprehension of bioremediation are not too far off. Specialists currently can culture microorganisms that are significant in bioremediation and can assess their physiology utilizing a mix of genome-empowered trial and displaying procedures. Moreover, new natural genomic systems offer the likelihood for comparable examinations on up 'til now uncultured life forms. Consolidating models that can foresee the action of microorganisms that are associated with bioremediation with existing geochemical and hydrological models ought to change bioremediation from a largely empirical practice into a science.

\section{References:-}

1. Hemapriya, J and S.Vijayanand. (2013). Bioremediation of Structurally different textile dyes by a novel bacterial consortium. Int.J.Curr.Microbiol.Appl.Sci., 2(11):212-226.

2. Joshi, T., L.Iyengar, K.Singh and S.Garg. (2008). Isolation, Identification and application of novel bacterial consortium TJ-1 for the decolorization of structurally different azo dyes. Bioresour. Technol., 99:7115-7121.

3. Kalyani,D.C., A.A.Telke, R.S.Dhanve and J.P.Jadhav. (2009). Eco-friendly biodegradation and detoxification of Reactive Red-2 textile dye by newly isolated Pseudomonas sp. SUK1. J. Haz. Mat., 163:735-742.

4. Moosvi, S., X.Kher and D.Madamwar. (2007). Isolation, characterization and decolorization of textile dyes by a mixed bacterial consortium JW-2.Dyes. Pigments., 74:723-729.

5. Parshetti, G., S.Kalme, G.Saratale and S.Govindwar. (2006). Biodegradation of Malachite Green by Kocuria rosea MTCC 1532. Acta Chim. Slov., 53:492-498.

6. Robinson, T., G.McMullan, R.Marchant and P.Nigam. (2001). Remediation of dyes in textile effluent: A critical review on current treatment technologies with a proposed alternative. Bioresour. Technol., 77:247-255.

7. Suzuki, Y., T.Yoda, A.Rahul and W.Sagiura. (2001). Molecular cloning and characterization of the gene encoding azoreductase from Bacillus sp. OY 1-2 isolated from soil. J. Biol. Chem., 246:9059-9065.

8. Vandevivere, P.C., R.Bianchi and W.Verstraete. (1998). Treatment of reuse of wastewater from the textile wetprocessing industry: Review of emerging technologies. J. Chem. Technol. Biotechnol., 72:289-302.

9. Walker, G.M. and L.R.Weatherley. (2000). Biodegradation and biosorption of acid anthraquinone dye. Environ. Pollut., 108:219-223. 